\title{
As bases de dados de publicações e a Revista Brasileira de Ginecologia e Obstetrícia
}

\section{Publication databases and Revista Brasileira de Ginecologia e Obstetricia}

A base de dados de referências Scopus contém informações sobre publicações em várias áreas da ciência e inclui textos de outras fontes, além dos periódicos regulares. O site SJR/ SCImago produz uma série de indicadores sobre periódicos e trabalhos científicos publicados, os quais incluem o índice SJR, que indica o número de citações em dois ou três anos de trabalhos publicados nos periódicos incluídos na base de dados Scopus da editora Elsevier. De certa forma, o índice SJR pode ser empregado como o 'fator de impacto', obtido do Science Citation Index (ISI Thomson Reuters ${ }^{\circledR}$ ). No entanto, uma diferença importante é que aquele índice inclui no cálculo o prestígio do periódico, no qual a citação é feita e não apenas o número de citações recebidas.

$\mathrm{Na}$ área de Medicina é possível acessar as informações referentes aos periódicos de cada especialidade. Entre os vários parâmetros de avaliação do desempenho das revistas, o mais importante é o SJR (SCImago ranking), que avalia o impacto das revistas e mostra o número médio de citações que os trabalhos publicados nos últimos três anos receberam no âmbito dos periódicos incluídos no sistema Scopus. Para 2011 o periódico com o maior índice na área de Ginecologia e Obstetrícia foi o Human Reproduction Update, com um SJR de 0,791 ${ }^{1}$. Em segundo lugar apareceu a Gynecologic Oncology, com 0,374. Essa enorme diferença entre as duas conhecidas revistas deve-se provavelmente ao fato de a Human Reproduction Update (HRU) publicar uma grande quantidade de revisões, o que eleva bastante o número de artigos citados e o de citações por trabalho - tendência esta já destacada em outras análises bibliométricas².

A Revista Brasileira de Ginecologia e Obstetrícia (RBGO) aparece em $83^{\circ}$ lugar nesta lista de um total de 149 publicações da especialidade, indexadas nesta base de dados. É precedida por um conjunto de revistas, que inclui, quase que exclusivamente, periódicos dos Estados Unidos, do Reino Unido, da Holanda e do Canadá. Como exceções e com melhor classificação do que a RBGO, há apenas duas revistas da Austrália e uma da Coreia do Sul (Journal of Gynecologic Oncology, com índice SJR de 0,107). Em tal colocação, a presente revista é a primeira publicada fora do conjunto de países mencionados, com um SJR de 0,37. Mais importante que a pontuação obtida em 2011 (último ano disponível), é verificar a evolução do impacto da revista. No índice de 2008 (primeiro ano em que foi possível avaliar o número de citações obtido pelos trabalhos durante três anos após publicação), a RBGO

Correspondêncio Jurandyr Moreira de Andrade Departamento de Ginecologia e Obstetrício Avenida Bandeirantes, 3.900 (EP: 14049-900 Ribeirão Preto (SP), Brasil
'Editor da Revista Brasileira de Ginecologia e Obstetrícia, Brasil.

Conflito de interesses: não há. 
estava em $95^{\circ}$ lugar com índice de 0,028 , precedida por várias revistas de países em desenvolvimento ${ }^{1}$.

Como no período entre 2008 e 2012 a revista havia publicado poucos trabalhos em inglês, deduziu-se que uma parte das citações obtidas pelos trabalhos publicados na RBGO é proveniente das poucas revistas em espanhol, e a maior parte é devido ao acesso aos abstracts por leitores/ autores do exterior. De fato esta hipótese coincide com os dados fornecidos pelas estatísticas da base de dados SciELO. É inegável que um componente importante da visibilidade dos trabalhos é o acesso aos resumos e abstracts, pois é a partir da leitura desta seção que o leitor opta pela leitura do texto completo. É notável, portanto, que, entre agosto de 2009 a agosto de 2012, ou seja nos últimos três anos, estas seções dos trabalhos da RBGO tenham sido acessadas 190.000 vezes por leitores de língua inglesa; 120.000 por leitores de espanhol e 320.000 de idioma não especificado ${ }^{3}$.

No entanto, temos que reconhecer que o total destes acessos é pequeno, considerando os mais de seis milhões de acessos aos resumos e abstracts da Revista ${ }^{3}$. Embora não seja recomendado que um trabalho seja citado a partir da leitura do resumo ou abstract, é certo que a leitura dos mesmos levará à procura de outros textos dos mesmos autores em inglês sobre assuntos semelhantes ou a versão para o inglês, empregando-se os tradutores on-line. Concluímos, portanto, com um alerta para os autores de trabalhos, sobre a necessidade da apresentação cuidadosa das informações sobre o trabalho no resumo e, claro, no abstract.
A repercussão de um trabalho pode ser medida pelo número de citações que recebe em outros artigos ou, secundariamente, pelo número de leitores ou acessos nas bases de dados. Entre as estatísticas disponíveis no sistema SciELO, está o número de acessos para os trabalhos publicados nos periódicos indexados. Este indicador particularmente fornece a quantidade de acessos efetuados pelos visitantes do SciELO aos trabalhos completos ${ }^{4}$. Durante 2012, a RBGO é o periódico especializado da área clínico-cirúrgica, cujos trabalhos foram os mais acessados em 2007 (total de 1.591.161). Em segundo lugar, ainda na mesma área, está a Revista Brasileira de Otorrinolaringologia, com 928.782. Esta revista tem sido, também, o sexto periódico mais acessado entre todos os da área da saúde.

Ainda sobre a questão da visibilidade dos trabalhos publicados na RBGO, desde o início de 2012 passou-se a publicar também em inglês e em espanhol, seja para autores nacionais ou do exterior ${ }^{5}$. É certo que a aceitação de trabalhos em inglês tornará a produção científica publicada nesta revista mais lida e citada. No entanto, é preciso lembrar que a linguagem empregada seja adequada para estimular a leitura, ao invés de inibi-la, o que certamente ocorrerá com textos inadequadamente vertidos para o inglês. Neste caso, o leitor do exterior vai preferir ler um trabalho do qual possa eventualmente obter uma tradução automática do texto ou partes dele do português. Por este motivo, temos solicitado aos autores que peçam assessoria de tradutores ou revisores profissionais antes do envio do texto para análise. Desta forma, além da vantagem exposta, será possível encaminhar o trabalho para análise por referees do exterior.

\section{Referências}

1. SJR SClmago Journal \& Country Rank [Internet]. SCimago Lab; 2007-12 [cited 2012 Ago 10]. Available from: <http://www. scimagojr.com/journalrank. php? category $=2729 \&$ area $=2700 \&$ year $=2011$ \&country=\&order=sjr\&min=0\&min_type $=c d>$

2. Rocha e Silva M. Qualis 2011-2013: os três erres. Clinics. 2010;65(10):935-6.

3. SciELO Scientific Electronic Library Online [Internet]. Relatórios de utilização do site: resumo de acessos aos artigos das revistas por idioma. 2012 [citado 2012 Set 3]. Disponível em: <http:// scielo-log.scielo.br/scielolog/scielolog.php? script= sci_journalst atlang\&pid=\&lng=pt\&nrm=iso\&order=1 \&dti=20090801 \&dtf=2 $0120930 \& a p p=s c i e l o \& s e r v e r=w w w . s c i e l o . b r>$

4. SciELO Scientific Electronic Library Online [Internet]. Relatórios de utilização do site: resumo de acessos às revistas por idioma. 2012 [citado 2012 Set 3]. Disponível em: <http://scielo-log. scielo.br/scielolog/scielolog.php? script=sci_journalstat\&pid=\&l $\mathrm{ng}=\mathrm{pt \& nrm}=\mathrm{iso} \&$ order $=4 \& \mathrm{dti}=20120101 \& \mathrm{dtf}=20120930 \& a p$ $\mathrm{p}=$ scielo\&server $=>$

5. Andrade JM. To improve the visibility of Brazilian papers in Obstetrics and Gynecology. Rev Bras Ginecol Obstet. $2011 ; 33(2): 63-7$. 